\title{
Bacteria-induced egg hatching differs for Trichuris muris and Trichuris suis
}

\author{
Nermina Vejzagić ${ }^{*}$, Roberto Adelfio ${ }^{2,3}$, Jennifer Keiser ${ }^{2,3}$, Helene Kringel ${ }^{4}$, Stig Milan Thamsborg ${ }^{4,5}$ \\ and Christian M.O. Kapel ${ }^{1,4}$
}

\begin{abstract}
Background: Eggs of the porcine whipworm Trichuris suis are currently explored in human clinical trials as a treatment of immune-mediated diseases. In this context, only the infective, embryonated eggs, constitute the Active Pharmaceutical Ingredient (API). The rodent whipworm, Trichuris muris is commonly used as a laboratory model to study Trichuris biology. The embryonated eggs (containing a fully developed larva) are biologically active and will invade the large intestinal mucosa of the host. This study aims to assess the in vitro hatching of $T$. muris and T. suis eggs in various bacterial cultures as a measure for their biological activity.

Methods: Eggs of T. muris and T. suis were incubated with Escherichia coli strain (BL-21) at three concentrations in a slightly modified in vitro egg hatching assay previously developed for T. muris. Additionally, E. coli strains (M15, SG13009, PMC103, JM109, TUNER, DH5alpha, TOP10) and five Gram-positive bacteria (Enterococcus caccae, Streptococcus hyointestinalis, Lactobacillus amylovorus, L. murinus, and L. reuteri) were tested as a hatching stimulus for T. muris and T. suis eggs.
\end{abstract}

Results: Whereas T. muris eggs hatched, T. suis did not, even when exposed to different concentrations and strains of E. coli after 4 and 24-hour incubation. When incubated with Gram-positive bacteria, only T. muris eggs showed noticeable hatching after $20 \mathrm{~h}$, although with high variability.

Conclusions: The observed difference in hatching of T. muris and T. suis eggs incubated with selected bacteria, indicate significant biological differences which may reflect specific adaptation to different host-specific gut microbiota.

Keywords: Trichuris muris, Trichuris suis, In vitro, Egg hatching, Bacteria

\section{Background}

Trichuris muris and T. suis, whipworms of mice and pigs, respectively, invade the mucosa of the large intestine [1-3]. The life cycle is direct with embryonated eggs (each containing a fully developed larva) as infective stage $[1,3]$. The embryonated eggs of $T$. suis (TSO) represent a raw material of the Active Pharmaceutical Ingredient (API) in a medicinal product, which is currently being explored as a treatment for patients with immune-mediated diseases. Such helminthic therapy is founded on the hygiene hypothesis [4] or more broadly, the 'Old friends' hypothesis $[5,6]$. In more details, a positive immunomodulatory effect of TSO has been

\footnotetext{
* Correspondence: nerminav@plen.ku.dk

'Section for Organismal Biology, Department of Plant and Environmental Sciences, Faculty of Science, University of Copenhagen, Frederiksberg C, Denmark

Full list of author information is available at the end of the article
}

demonstrated in patients with inflammatory bowel disease [7-9] and multiple sclerosis [10], although this positive immunomodulatory effect was not demonstrated in a safety and efficacy study in patients with multiple sclerosis [11]. The treatment with TSO is well-tolerated in patients and only transient gastrointestinal symptoms are present following first dosing [10-15].

A first requirement to use TSO as a medicinal drug is that the eggs are biologically active, i.e. that the eggs are able to hatch for the release of larvae. Description of eggs based solely on their morphological development and appearance of larvae inside does not necessarily correlate with the egg hatchability, as larvae may degenerate over an extended period of storage.

In recent years, individual bacterial species were successfully used for hatching T. muris eggs under in vitro conditions [16-18]. However, whether T. suis eggs share 
the same egg hatching stimulation as T. muris eggs is still unknown. Therefore, in the present study a slight modification of a published method based on Gram-negative Escherichia coli (BL-21) for hatching T. muris eggs [16] was employed to test whether $T$. muris and $T$. suis eggs show different ability to hatch when incubated under the same conditions. Further, eggs of the two Trichuris species were incubated with five Gram-positive bacteria.

Here we report how two very closely related nematodes (same genus) respond differently to in vitro hatching when incubated with selected Gram-negative and Gram-positive bacteria.

\section{Methods}

\section{Parasite batches}

Eggs of T. muris were isolated from faeces of experimentally infected female mice (C57BL/10ScSnOlaHsd) and were embryonated for 3 months at room temperature $\left(23-24{ }^{\circ} \mathrm{C}\right.$ ) in Milli-Q (ultrapure water purified by filtration and deionization) and in sulphuric acid $\left(\mathrm{H}_{2} \mathrm{SO}_{4}\right)$ $\mathrm{pH} 1$, respectively.

Eggs of T. suis were isolated from faeces of experimentally infected female Göttingen minipigs (Ellegaard Göttingen Minipigs A/S, Dalmose, DK). The eggs were embryonated in $\mathrm{H}_{2} \mathrm{SO}_{4} \mathrm{pH} 1$ for 100 days ( \pm 10 days) at $25{ }^{\circ} \mathrm{C}$ and then stored at $5{ }^{\circ} \mathrm{C}\left(2-8{ }^{\circ} \mathrm{C}\right)$.

Stabilized $\mathrm{H}_{2} \mathrm{SO}_{4} \mathrm{pH} 1$ was prepared by adding $94 \mathrm{ml}$ $1 \mathrm{M} \mathrm{H}_{2} \mathrm{SO}_{4}, 36 \mathrm{mg}$ potassium sulphate and $1236 \mathrm{mg}$ sodium sulphate in $1000 \mathrm{ml}$ distilled water to prevent any bacterial and fungal growth during storage of $T$. suis eggs. Storage in sulphuric acid is not known to affect either the development or the infectivity of $T$. suis eggs [19]. Also, $0.1 \mathrm{~N} \mathrm{H}_{2} \mathrm{SO}_{4}$ has been used as an embryonation medium for Ascaris suum eggs [20].

To secure comparable preparatory conditions for the batches in the experiment with Gram-positive bacteria, the medium of one $T$. muris batch was changed to $\mathrm{H}_{2} \mathrm{SO}_{4} \mathrm{pH} 1$ and stored at $5{ }^{\circ} \mathrm{C}$, and the medium of one T. suis batch was changed to Milli-Q and stored at room temperature for 3 months.

Prior to use, all batches were transferred to Milli-Q.

\section{Bacteria}

The E. coli strains (BL-21, M15, SG13009, PMC103, JM109, TUNER, DH5alpha, TOP10) were incubated overnight in Luria Broth (Sigma-Aldrich) at $37{ }^{\circ} \mathrm{C}$ on a shaker (250 rounds per minute; rpm). The Grampositive bacteria Streptococcus hyointestinalis (DSM No. 20770) and Enterococcus caccae (DSM No. 19114) were cultured in tryptic soy broth (Sigma-Aldrich) with added yeast extract (Sigma-Aldrich). Lactobacillus amylovorus (DSM No. 16698, deposited by Dr. S. Konstantinov, Laboratory for Microbiology, Wageningen University and Research Centre Agrotechnology \& Food Sciences,
Wageningen, The Netherlands), Lactobacillus murinus (DSM No. 20452), and Lactobacillus reuteri (DSM No. 20016) were cultured in MRS broth (Sigma-Aldrich). Cultures were incubated overnight in the presence of $\mathrm{CO}_{2}$ on a shaker at $37^{\circ} \mathrm{C}$ (range $220-275 \mathrm{rpm}$ ).

The optical density (OD) was measured on SpectraMax M2 (Molecular Devices) at $600 \mathrm{~nm}$ (absorbance). The concentration was calculated using E. coli formula: $\mathrm{OD} \times 5 \times 10^{8}=$ bacteria $/ \mathrm{ml}[16]$.

\section{Incubation with Escherichia coli}

A total of 1000 embryonated eggs per well were plated on 24-well plates in RPMI (1640, W/HEPES; CE, GIBCO) with $5 \%$ penicillin (Invitrogen, $100 \mathrm{U} / \mathrm{ml}$ ) -streptomycin (Invitrogen, $100 \mu \mathrm{g} / \mathrm{ml}$ ) and $5 \%$ amphotericin B (Sigma-Aldrich A2942, $250 \mu \mathrm{g} / \mathrm{ml}$ ) together with an $E$. coli suspension.The samples were incubated at $36{ }^{\circ} \mathrm{C}$ and examined after 4 and 24 hours. The BL-21 strain ( $E$. coli strain used for hatching $T$. muris eggs as described in [16]) was tested at three concentrations $\left(5 \times 10^{8}, 10 \times 10^{8}\right.$ and $20 \times 10^{8}$ bacteria/ml $)$, while the other E. coli strains were tested at one concentration $\left(5 \times 10^{8}\right.$ bacteria/ml). After the incubation, the wells with $T$. muris eggs were examined for hatching in subsamples (4-5 × $20 \mu \mathrm{l}$ ), whereas entire wells were examined for $T$. suis eggs.

Furthermore, the E. coli hatching assay was performed on T. muris eggs embryonated in Milli-Q or $\mathrm{H}_{2} \mathrm{SO}_{4} \mathrm{pH} 1$ in concentrations of 600-1500 embryonated eggs in $3 \mathrm{ml}$, according to the original method. The number of released larvae was examined in subsamples for $n=4$ per group.

\section{Incubation with Gram-positive bacteria}

A suspension of Gram-positive bacterium $\left(5 \times 10^{8}\right.$ bacteria/ml) was mixed with Trichuris eggs, and five aliquots of approximately 100 embryonated eggs per well were plated on a 96-well plate. Plates were flushed with $\mathrm{CO}_{2}$ and incubated in RPMI-1640 alone or RPMI-1640 containing $5 \%$ penicillin-streptomycin and $5 \%$ amphotericin $\mathrm{B}$ at $37{ }^{\circ} \mathrm{C}$. The samples were examined after 4 and $20 \mathrm{~h}$.

In all experiments, released larvae were enumerated using an inverted microscope (Carl Zeiss Primo Vert).

\section{Statistical analysis}

Data was analyzed in GraphPad Prism software (version 6) and $\mathrm{R}$ version 3.1.2 (R Core Team, 2014). Hatching percentage was calculated based on the number of released larvae and the number of embryonated eggs added per well. Data was $\log$ transformed as $y=\log (y+1)$ whenever necessary to fulfill requirements of the normal distribution for the analysis. One-way ANOVA was used to test the effect of different $E$. coli (BL-21) concentrations on T. muris egg hatching after 4 , and $24 \mathrm{~h}$, followed by the Tukey's post hoc test for 
multiple comparisons. The effects of different $E$. coli strains and the time of incubation on T. muris egg hatching were evaluated with the two-way ANOVA. Since the hatching in the control groups was absent or close to 0 , they were not included in the analysis of ANOVA. An unpaired Student's $t$ test was used for pairwise comparisons. Generalized linear mixed model (glmm) fit by maximum likelihood (Laplace approximation) (Bates D, Maechler M, Bolker B and Walker S, 2014; R package version 1.1-7) was used to test the influence of different bacteria and the type of egg storage medium (Milli-Q and $\mathrm{H}_{2} \mathrm{SO}_{4} \mathrm{pH} 1$ ) on overnight T. muris egg hatching in RPMI-1640 without antimicrobials. As data contained too many 0 values, the interaction between bacteria and the type of egg storage medium (Milli-Q and $\mathrm{H}_{2} \mathrm{SO}_{4} \mathrm{pH} 1$ ) was not included in the analysis. Values of $p<$ 0.05 were considered statistically significant.

\section{Ethical approval for animal use}

The experimentation on mice was approved by the local veterinary agency based on Swiss cantonal and national regulations (permission no. 2070), and on minipigs by the Animal Experiments Inspectorate, Ministry of Food, Agriculture and Fisheries of Denmark (permission no: 2012-15-2934-00641).

\section{Results}

\section{Egg hatching with Escherichia coli}

After $4 \mathrm{~h}$ incubation, the two lowest concentrations of $E$. coli (BL-21) tested $\left(5 \times 10^{8}\right.$ and $10 \times 10^{8}$ bacteria/ml) resulted in significantly higher $T$. muris egg hatching than a concentration of $20 \times 10^{8}$ bacteria $/ \mathrm{ml}\left(\mathrm{F}_{2,9}=54.20, p<\right.$ 0.0001; Tukey's post hoc test $p<0.0001)$. However, no significant difference could be demonstrated after $24 \mathrm{~h}$ $\left(F_{2,9}=0.93, p=0.43\right)$. No hatching was observed for $T$. suis at any concentration tested (Table 1 ).

The strain of $E$. coli (ANOVA F $\mathrm{F}_{7}, 32=3.52, p=0.01$ ) and the time of incubation (ANOVA $F_{1,32}=12.97, p=0.001$ ) had a significant effect on the hatching of T. muris eggs (Fig. 1). None of the E. coli strains evaluated induced

Table 1 Hatching of Trichuris muris and T. suis eggs after incubation with Escherichia coli (BL-21)

\begin{tabular}{|c|c|c|c|c|}
\hline \multirow{3}{*}{$\begin{array}{l}\text { Escherichia coli } \\
\text { concentration/ml }\end{array}$} & \multicolumn{4}{|c|}{ Average hatching percentage $( \pm S D)$} \\
\hline & \multicolumn{2}{|c|}{$4 \mathrm{~h}$} & \multicolumn{2}{|c|}{$24 \mathrm{~h}$} \\
\hline & T. muris & T. suis & T. muris & T. suis \\
\hline $5 \times 10^{8}$ & $83.9( \pm 12.9)$ & $0.1( \pm 0.1)$ & $80.5( \pm 16.9)$ & $0.1( \pm 0.1)$ \\
\hline $10 \times 10^{8}$ & $57.0( \pm 1.4)$ & $0.0( \pm 0.1)$ & $70.5( \pm 4.8)$ & $0.1( \pm 0.1)$ \\
\hline $20 \times 10^{8}$ & $13.5( \pm 4.8)$ & $0.0( \pm 0.0)$ & $72.0( \pm 21.8)$ & $0.0( \pm 0.0)$ \\
\hline Controls (no E. coli) & $0.0( \pm 0.0)$ & $0.2( \pm 0.2)$ & $0.1( \pm 0.1)$ & $0.2( \pm 0.2)$ \\
\hline
\end{tabular}

Trichuris eggs incubated with three different concentrations of $E$. coli (BL-21) in RPMI- 1640 with $5 \%$ penicillin-streptomycin and $5 \%$ amphotericin B after 4 and $24 \mathrm{~h}$ incubation at $36^{\circ} \mathrm{C}$. The controls are Trichuris eggs incubated without the $E$. coli; $\mathrm{n}=4$ per group hatching of $T$. suis eggs after 4 and $24 \mathrm{~h}$ incubation (average hatching was less than $0.2 \%$ ).

No significant difference in hatching was observed for T. muris eggs embryonated in $\mathrm{H}_{2} \mathrm{SO}_{4} \mathrm{pH} 1(10.9 \pm 6.3 \%)$ (mean \pm S.D.) and in Milli-Q $(21.1 \pm 8.4 \%)$ after $4 \mathrm{~h}$ with E. coli at $37^{\circ} \mathrm{C}\left(5 \times 10^{8}\right.$ bacteria $\left./ \mathrm{ml}\right)\left(\mathrm{t}_{6}=1.9, p=0.10\right)$.

\section{Egg hatching with Gram-positive bacteria}

After $4 \mathrm{~h}$, no significant hatching could be demonstrated for T. muris incubated with any of the Gram-positive bacteria in any incubation media (the highest average hatching was $0.6 \%$ ). After $20 \mathrm{~h}, E$. caccae (z value $=4.26$, $p<0.001$ ) and $L$. reuteri ( $\mathrm{z}$ value $=3.42, p<0.001$ ) induced significantly higher hatching of T. muris eggs as compared to the controls. The effect of $L$. reuteri on egg hatching did not significantly differ from $E$. caccae ( $p=0.62)$ (Fig. 2). However, high variation was observed in and in-between experiments with the same bacterium.

None of the tested bacteria induced significant hatching of $T$. suis eggs after 4 (average hatching less than $0.4 \%$ ) or $20 \mathrm{~h}$ post-incubation (Fig. 3).

Samples incubated with antimicrobials showed consistently low egg hatching of T. muris (Fig. 4) and T. suis eggs (average hatching was less than $0.6 \%$ ) after $20 \mathrm{~h}$ incubation. In all experiments, the control group with whipworm eggs without the addition of bacteria had low hatching (average hatching less than $0.5 \%$ ).

\section{Discussion}

The use of individual bacterial species [16-18] or contents from the caecum $[18,21,22]$ and the upper colon [22] in hatching T. muris eggs, points to close interactions between commensal bacteria and parasites within their niche. Such interactions may also explain observations of parasite's ability to modulate the intestinal microbiota [23-27], as shown by an increase of lactobacilli during chronic T. muris infection [26]. In the large intestine of Göttingen minipigs and mice, microbiota is primarily composed of the phyla Firmicutes and Bacteroidetes [28-30], while Proteobacteria comprises $0.6 \%$ in Göttingen minipigs [28].

In the present study, T. muris eggs hatched with E. coli (Proteobacteria), E. caccae (Firmicutes), S. hyointestinalis (Firmicutes), L. reuteri, and L. amylovorus (Firmicutes), while $T$. suis had overall very low hatching. However, $T$. muris egg hatching was inconsistent and highly variable with the Gram-positive bacteria.

Due to dietary differences between a mouse and a pig, host-specific bacterial composition may account for the observed discrepancy in the hatching of eggs of the two whipworm species. Although only a few bacteria were presently selected for comparison, selected bacterial species belong to the genera associated with pig and mouse intestinal tract. 


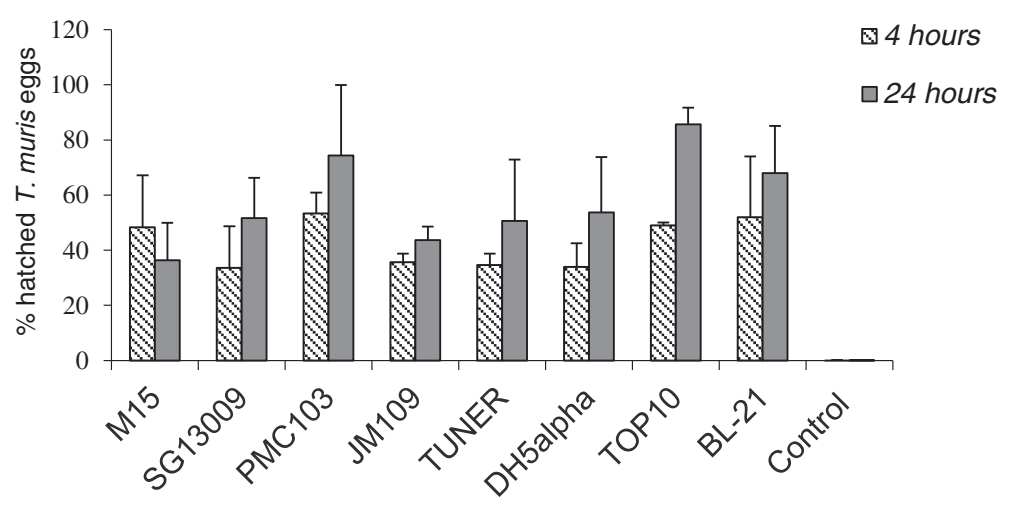

Fig. 1 Trichuris muris eggs incubated with different Escherichia coli strains. Samples were incubated for 4 and 24 hours at $36^{\circ} \mathrm{C}$. The control group represents T. muris eggs incubated without the addition of E. coli. Arithmetic mean (bar) and standard deviation (error bars) for $\mathrm{n}=3$ per group

Different bacteria may have different mechanisms in which they trigger eggs to hatch. Hayes et al. reported that T. muris eggs hatched through close physical contact with E. coli, and suggested that other mechanisms may exist for Pseudomonas aeruginosa and Staphylococcus aureus [18]. Since the large intestine contains a diverse microbial community (mostly anaerobes) [31], it is possible that a combination of different bacteria with their specific mechanisms, rather than one specific bacterium, is needed to hatch $T$. suis eggs. Whether a specific bacteria-induced hatching pattern is characteristic of other whipworms eggs (e.g. T. trichiura and T. vulpis) is still undefined. While Areekul et al. reported T. trichiura and T. vulpis co- infections in stools of $10.7 \%$ Trichuris positive children in Thailand [32], other reported human cases of T. vulpis infection are brought into question (reviewed in [33]).

On the other hand, the similarities between pig and human gut microbiota (reviewed in [34]) and positive treatment effect of $T$. suis eggs in patients with immunemediated diseases [7-10], indicate that $T$. suis eggs hatch in the human gut. In addition, pigs have been experimentally cross-infected with $T$. trichiura, although the development did not reach a patent infection [35]. Therefore, it can be speculated that a common bacterial stimulus exists between T. suis and T. trichiura. Recently, a mix of $T$. trichiura and $T$. suis sequence

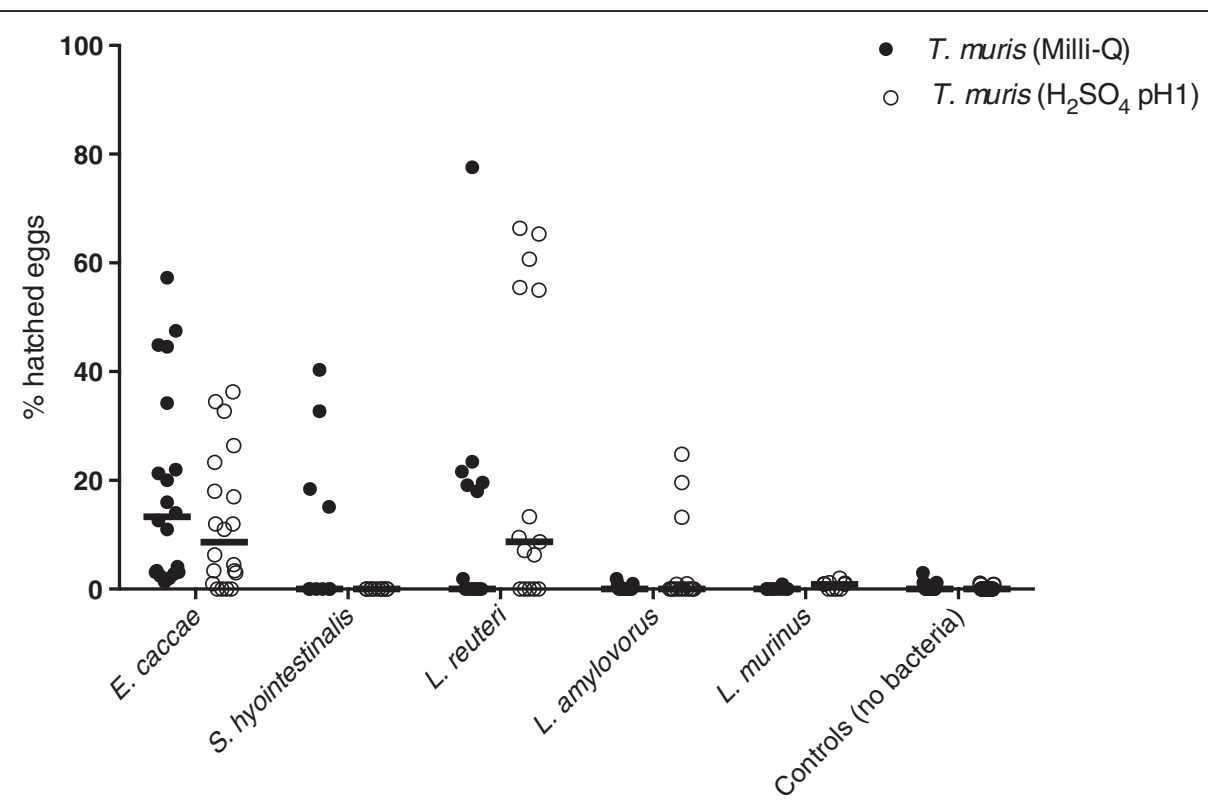

Fig. 2 Trichuris muris eggs incubated with Gram-positive bacteria in RPMI-1640 without antimicrobials. Samples were incubated for 20 hours at $37^{\circ} \mathrm{C}$. Individual counts of T. muris (Milli-Q or $\mathrm{H}_{2} \mathrm{SO}_{4} \mathrm{pH} 1$ ) and median for all experiments with Enterococcus caccae $(\mathrm{n}=20)$, Streptococcus hyointestinalis $(n=10)$, Lactobacillus reuteri $(n=15)$, L. amylovorus $(n=15)$, and L. murinus $(n=10)$. Controls represent T. muris eggs incubated without the addition of bacteria $(n=25)$ 


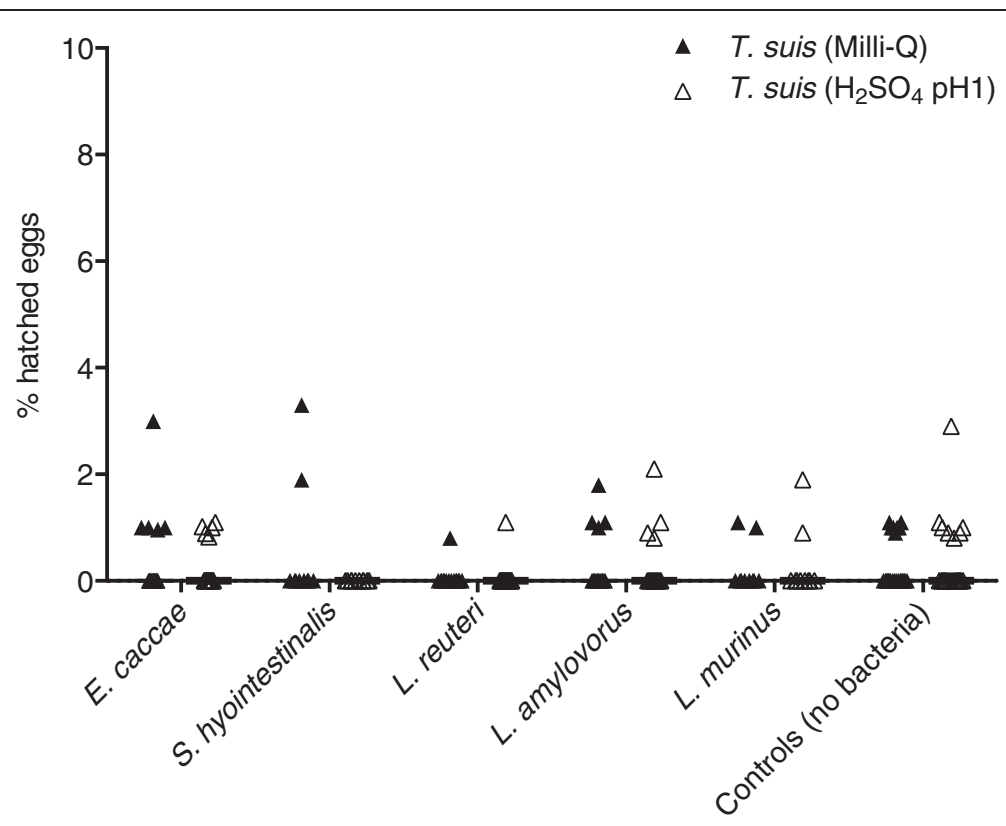

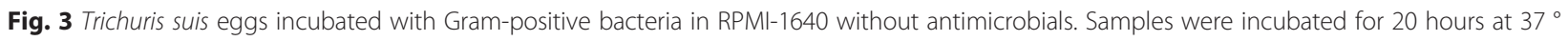
C. Individual counts of $\mathrm{T}$. suis (Milli-Q or $\mathrm{H}_{2} \mathrm{SO}_{4} \mathrm{pH} 1$ ) and median for all experiments with Enterococcus caccae $(\mathrm{n}=20)$, Streptococcus hyointestinalis $(n=10)$, Lactobacillus reuteri with T. suis in Milli-Q $(n=15)$, L. reuteri with T. suis in $\mathrm{H}_{2} \mathrm{SO}_{4} \mathrm{pH} 1(n=20)$, L. amylovorus $(n=15)$, and $L$. murinus $(n=10)$. Controls represent $T$. suis eggs without the addition of bacteria $(n=25)$

types was identified in three human-originating worms [36]. Even though a few studies either observed the presence of a single male adult worm in the human gut [37] or low grade $T$. suis egg excretion under experimental infections [35, 38], humans are not considered either natural or suited host for T. suis. Furthermore, during repeated dosing in clinical studies, $T$. suis eggs are absent in the stool samples $[8,9]$, which underline that patent $T$. suis infection is limited to pigs, where the full life cycle is confined.

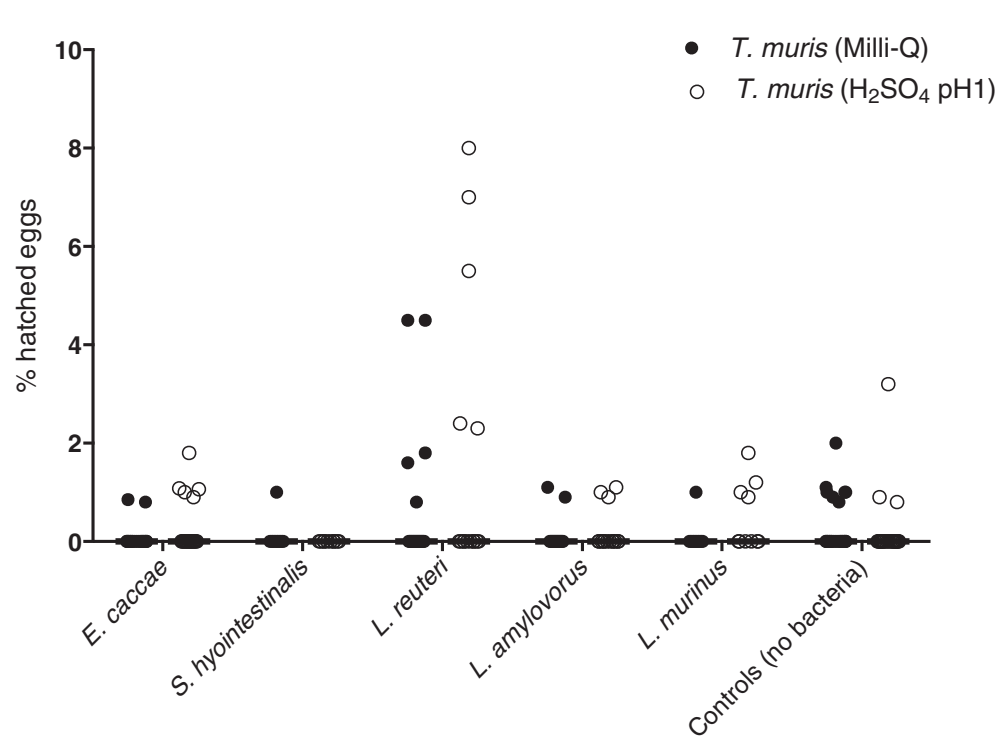

Fig. 4 Trichuris muris eggs incubated with Gram-positive bacteria in RPMI-1640 with antimicrobials. Samples were incubated for 20 hours at $37^{\circ} \mathrm{C}$. Individual counts of $\mathrm{T}$. muris (Milli-Q or $\mathrm{H}_{2} \mathrm{SO}_{4} \mathrm{pH}$ ) and median for all experiments with Enterococcus caccae $(\mathrm{n}=20)$, Streptococcus hyointestinalis $(n=10)$, Lactobacillus reuteriwith T. muris in Milli-Q $(n=20)$, Lactobacillus reuteri with T. muris in $\mathrm{H}_{2} \mathrm{SO}_{4} \mathrm{pH}(\mathrm{n}=15), \mathrm{L}$. murinus $(\mathrm{n}=10)$, and L. amylovorus $(n=15)$. Controls represent $T$. muris eggs without the addition of bacteria $(n=25)$ 
Although the present study tested a limited number of bacteria, our findings together with previous limited observations on Trichuris cross-species transmission, suggests that Trichuris has a narrower host-specificity window compared to other nematodes, such as Ascaris [39].

To further study the parasite-bacteria interaction and host-parasite specificity, T. suis and T. muris eggs may be cross-incubated with mucosal scrapings from the intestine of a mouse and pig, respectively. Inclusion of other whipworm species in such experiment, e.g. human T. trichiura and canine T. vulpis, may provide further insight into the specific parasite adaptation to the host gut environment.

\section{Conclusions}

The present study is the first to compare eggs of two whipworm species in relation to bacterial-dependent hatching. Although T. muris successfully hatched in the presence of the different $E$. coli strains, the egg hatching showed high variability in the presence of five tested Gram-positive bacteria after overnight incubation without the addition antimicrobials. In contrast, none of the tested bacteria triggered hatching of $T$. suis eggs. This suggests that the co-evolution of the parasite and host, and the adaptation to host's microbiota has resulted in unique host-specific hatching stimuli of T. muris and T. suis eggs.

\section{Competing interests}

HK, SMT, and CK are employed by Parasite Technologies A/S, a company that is GMP-licensed by the Danish Medicines Agency for production of T. suis eggs.

\section{Authors' contributions}

$N V, R A, J K, H K, S M T$, and CK designed the study. NV and RA carried out the experimental work. NV and SMT discussed and NV performed the statistical analysis. NV, RA, JK, HK, SMT, and CK wrote the manuscript. All authors read and approved the final manuscript.

\section{Acknowledgements}

Late Dr. Allan Roepstorff is acknowledged for the discussion on the study conception. Laboratory technicians Niels Peter Hansen and Charlotte Fischer are thanked for arranging the transportation of $T$. suis eggs. This study was supported by Parasite Technologies A/S, PhD scholarship from the Faculty of Science, University of Copenhagen and the European Research Council (ERC-2013-CoG 614739-A_HERO to J.K.).

\begin{abstract}
Author details
${ }^{1}$ Section for Organismal Biology, Department of Plant and Environmental Sciences, Faculty of Science, University of Copenhagen, Frederiksberg C, Denmark. ${ }^{2}$ Medical Parasitology and Infection Biology, Swiss Tropical and Public Health Institute, Basel, Switzerland. ${ }^{3}$ University of Basel, Basel, Switzerland. ${ }^{4}$ Parasite Technologies A/S, Hørsholm, Denmark. ${ }^{5}$ Parasitology and Aquatic Diseases, Department of Veterinary Disease Biology, Faculty of Health and Medical Sciences, University of Copenhagen, Frederiksberg C, Denmark.
\end{abstract}

Received: 14 March 2015 Accepted: 6 July 2015

Published online: 15 July 2015

\section{References}

1. Beer RJ. Studies on the biology of the life-cycle of Trichuris suis Schrank, 1788. Parasitology. 1973;67(3):253-62.
2. Tilney LG, Connelly PS, Guild GM, Vranich KA, Artis D. Adaptation of a nematode parasite to living within the mammalian epithelium. J Exp Zool A Comp Exp Biol. 2005;303(11):927-45.

3. Fahmy MAM. An investigation on the life cycle of Trichuris muris. Parasitology. 1954;44(1-2):50-7.

4. Strachan DP. Hay fever, hygiene, and household size. BMJ. 1989;299(6710):1259-60.

5. Rook GA. Review series on helminths, immune modulation and the hygiene hypothesis: the broader implications of the hygiene hypothesis. Immunology. 2009;126(1):3-11.

6. Rook GA, Adams V, Hunt J, Palmer R, Martinelli R, Brunet LR. Mycobacteria and other environmental organisms as immunomodulators for immunoregulatory disorders. Springer Semin Immunopathol. 2004;25(3-4):237-55.

7. Summers RW, Elliott DE, Qadir K, Urban Jr JF, Thompson R, Weinstock JV. Trichuris suis seems to be safe and possibly effective in the treatment of inflammatory bowel disease. Am J Gastroenterol. 2003;98(9):2034-41.

8. Summers RW, Elliott DE, Urban Jr JF, Thompson R, Weinstock JV. Trichuris suis therapy in Crohn's disease. Gut. 2005;54(1):87-90.

9. Summers RW, Elliott DE, Urban JF, Thompson RA, Weinstock JV. Trichuris suis therapy for active ulcerative colitis: a randomized controlled trial. Gastroenterology. 2005;128(4):825-32.

10. Fleming JO, Isaak A, Lee JE, Luzzio CC, Carrithers MD, Cook TD, et al. Probiotic helminth administration in relapsing-remitting multiple sclerosis: a phase 1 study. Mult Scler. 2011;17(6):743-54.

11. Voldsgaard A, Bager P, Garde E, Akeson P, Leffers A, Madsen C, et al. Trichuris suis ova therapy in relapsing multiple sclerosis is safe but without signals of beneficial effect. Mult Scler 2015. doi:10.1177/1352458514568173.

12. Sandborn WJ, Elliott DE, Weinstock J, Summers RW, Landry-Wheeler A, Silver $\mathrm{N}$, et al. Randomised clinical trial: the safety and tolerability of Trichuris suis ova in patients with Crohn's disease. Aliment Pharmacol Ther. 2013;38(3):255-63.

13. Bager P, Kapel C, Roepstorff A, Thamsborg S, Arnved J, Ronborg S, et al. Symptoms after ingestion of pig whipworm Trichuris suis eggs in a randomized placebo-controlled double-blind clinical trial. PLoS One. 2011;6(8):e22346.

14. Bourke CD, Mutapi F, Nausch N, Photiou DM, Poulsen LK, Kristensen B, et al. Trichuris suis ova therapy for allergic rhinitis does not affect allergen-specific cytokine responses despite a parasite-specific cytokine response. Clin Exp Allergy. 2012;42(11):1582-95.

15. Benzel F, Erdur H, Kohler S, Frentsch M, Thiel A, Harms L, et al. Immune monitoring of Trichuris suis egg therapy in multiple sclerosis patients. J Helminthol. 2012;86(3):339-47.

16. Wimmersberger D, Tritten L, Keiser J. Development of an in vitro drug sensitivity assay for Trichuris muris first-stage larvae. Parasit Vectors. 2013;6:42.

17. Koyama K. Evidence for bacteria-independent hatching of Trichuris muris eggs. Parasitol Res. 2013;112(4):1537-42.

18. Hayes KS, Bancroft AJ, Goldrick M, Portsmouth C, Roberts IS, Grencis RK. Exploitation of the intestinal microflora by the parasitic nematode Trichuris muris. Science. 2010;328(5984):1391-4.

19. Vejzagic N, Roepstorff A, Kringel H, Thamsborg SM, Nielsen MP, Kapel CM. Dose-dependent establishment of Trichuris suis larvae in Gottingen minipigs. Vet Parasitol. 2015;208(3-4):211-7.

20. Oksanen A, Eriksen L, Roepstorff A, llsoe B, Nansen P, Lind P. Embryonation and infectivity of Ascaris suum eggs. A comparison of eggs collected from worm uteri with eggs isolated from pig faeces. Acta Vet Scand. 1990;31(4):393-8.

21. Panesar TS, Croll NA. The hatching process in Trichuris muris (Nematoda: Trichuroidea). Can J Zool. 1981;59(4):621-8.

22. Panesar TS, Croll NA. The location of parasites within their hosts: site selection by Trichuris muris in the laboratory mouse. Int J Parasitol. 1980;10(4):261-73.

23. Li RW, Wu S, Li W, Navarro K, Couch RD, Hill D, et al. Alterations in the porcine colon microbiota induced by the gastrointestinal nematode Trichuris suis. Infect Immun. 2012;80(6):2150-7.

24. Wu S, Li RW, Li W, Beshah E, Dawson HD, Urban Jr JF. Worm burden-dependent disruption of the porcine colon microbiota by Trichuris suis infection. PLoS One. 2012;7(4):e35470.

25. Houlden A, Hayes KS, Bancroft AJ, Worthington JJ, Wang P, Grencis RK, et al. Chronic Trichuris muris infection in C57BL/6 mice causes significant changes in host microbiota and metabolome: effects reversed by pathogen clearance. PLoS One. 2015;10(5):e0125945. 
26. Holm JB, Sorobetea D, Kiilerich P, Ramayo-Caldas Y, Estelle J, Ma T, et al. Chronic Trichuris muris infection decreases diversity of the intestinal microbiota and concomitantly increases the abundance of lactobacilli. PLoS One. 2015;10(5):e0125495.

27. Rausch S, Held J, Fischer A, Heimesaat MM, Kuhl AA, Bereswill S, et al. Small intestinal nematode infection of mice is associated with increased enterobacterial loads alongside the intestinal tract. PLoS One. 2013;8(9):e74026.

28. Pedersen R, Ingerslev HC, Sturek M, Alloosh M, Cirera S, Christoffersen BO, et al. Characterisation of gut microbiota in Ossabaw and Gottingen minipigs as models of obesity and metabolic syndrome. PLoS One. 2013;8(2):e56612.

29. Nava GM, Friedrichsen HJ, Stappenbeck TS. Spatial organization of intestinal microbiota in the mouse ascending colon. ISME J. 2011;5(4):627-38.

30. Ley RE, Backhed F, Turnbaugh P, Lozupone CA, Knight RD, Gordon JI. Obesity alters gut microbial ecology. Proc Natl Acad Sci U S A. 2005;102(31):11070-5.

31. Flint HJ, Scott KP, Louis P, Duncan SH. The role of the gut microbiota in nutrition and health. Nat Rev Gastroenterol Hepatol. 2012;9(10):577-89.

32. Areekul P, Putaporntip C, Pattanawong U, Sitthicharoenchai $P$, Jongwutiwes S. Trichuris vulpis and T. trichiura infections among schoolchildren of a rural community in northwestern Thailand: the possible role of dogs in disease transmission. Asian Biomed. 2010;4(1):49-60

33. Traversa D. Are we paying too much attention to cardio-pulmonary nematodes and neglecting old-fashioned worms like Trichuris vulpis? Parasit Vectors. 2011;4:32.

34. Heinritz SN, Mosenthin R, Weiss E. Use of pigs as a potential model for research into dietary modulation of the human gut microbiota. Nutr Res Rev. 2013;26(2):191-209.

35. Beer RJ. The relationship between Trichuris trichiura (Linnaeus 1758) of man and Trichuris suis (Schrank 1788) of the pig. Res Vet Sci. 1976;20(1):47-54.

36. Nissen S, Al-Jubury A, Hansen TV, Olsen A, Christensen H, Thamsborg SM, et al. Genetic analysis of Trichuris suis and Trichuris trichiura recovered from humans and pigs in a sympatric setting in Uganda. Vet Parasitol. 2012;188(1-2):68-77.

37. Kradin RL, Badizadegan K, Auluck P, Korzenik J, Lauwers GY. latrogenic Trichuris suis infection in a patient with Crohn disease. Arch Pathol Lab Med. 2006;130(5):718-20.

38. Beer RJ. Experimental infection of man with pig whipworm. Br Med J. 1971;2(5752):44

39. Betson M, Nejsum P, Bendall RP, Deb RM, Stothard JR. Molecular epidemiology of ascariasis: a global perspective on the transmission dynamics of Ascaris in people and pigs. J Infect Dis. 2014;210(6):932-41.

\section{Submit your next manuscript to BioMed Central and take full advantage of:}

- Convenient online submission

- Thorough peer review

- No space constraints or color figure charges

- Immediate publication on acceptance

- Inclusion in PubMed, CAS, Scopus and Google Scholar

- Research which is freely available for redistribution 